\title{
"The Thing with Non-Physical Fatigue is that you can't Get Rid of it with Rest": Psychosocial Nursing Students Reflect on Their Clinical Placement, South Africa
}

Anna E Van den Heever ${ }^{*}$

University of the Witwatersrand, South Africa

*Corresponding author: Anna E Van den Heever, P.O Box 1654, Pinegowrie, 2123, Johannesburg, South Africa, Tel: +27 11 488-4061/4272, Fax: +27 11 488-4195; Email: annalie.vandenheever@wits.ac.za

Received date: November 30, 2016; Accepted date: February 21, 2017; Published date: February 25, 2017

Copyright: (C) 2017 Van den Heever AE. This is an open-access article distributed under the terms of the Creative Commons Attribution License, which permits unrestricted use, distribution, and reproduction in any medium, provided the original author and source are credited

\begin{abstract}
The emotions of childhood are intense and difficult to control, but over the years, they are mixed and moulded into more subtle and expressed feelings full of meaning and under cognitive control. During this process, people use certain defense mechanisms to deal with the pressure of their emotions, or deceive themselves about the actual conditions so that they can view reality as non-threatening. While the community's attitude towards people who live with a mental, physical or emotional disability or those who have been abused has been ranging from disregard, rejection and stigmatization to apathy; for health professionals and families of traumatized children, there seemed to be little opportunity to escape from the emotional and physical effects of being face to face with reality. Suggestions are that compassion fatigue could be due to psychological and physiological responses when working with and caring for traumatized people. A problem was identified during visits to the clinical facilities, when despite four years of exposure to general nursing, midwifery and community health; psychosocial nursing students expressed their fears of being traumatized by their experiences. Despite theoretical knowledge and practical training, they seemed to be in a state of emotional exhaustion. The question was asked: are nursing students emotionally prepared to work with severely emotionally, intellectually or physically traumatized children in the community?
\end{abstract}

The qualitative, descriptive study and psychodynamic approach was to explore and describe final year psychosocial nursing students' reflections and experiences during clinical placement with children who are traumatized by accidental or non-accidental injury or abuse. A purposive sample comprised of written and marked narratives from psychosocial reflective journals of 16 final (4th) year students until saturation of information was reached. Thematic analysis of the written narratives highlighted an emotional rollercoaster of feelings, ethical and professional conflict between the abused and being the abuser.

Keywords: Mental health; Student nurse; Abuse; Trauma; Defense mechanisms

\section{Introduction and Background}

People who suffered severe injuries or abuse need help and protection as a consequence of their cognitive, emotional and behavioral difficulties but what is often seen, is that those who care for them may suffer emotional and physical exhaustion. There is a tendency in society on the other hand, to stigmatise or deny the effects of traumatic events, which could be seen as an attempt to view reality as a non-threatening event [1].

There are many factors which may contribute to the prevalence of intellectual disabilities or neurodevelopmental disorders. Birth injuries are currently the most frequent cause of intellectual disabilities in South Africa. This means that adequate antenatal and maternity care is the first line of prevention and could decrease the incidence of intellectual disabilities [1].

In a study done in South Africa factors that predispose adults and children to violent injuries include poverty, unemployment, income inequality, patriarchal notions of masculinity, risk taking, defense of honor, weak parenting, firearms, alcohol, drug abuse, weakness in law reinforcement. Exposure to rape, child neglect, abuse, and partner violence are only some of the risk factors to the country's prevalence of health problems, which subsequently result in substance abuse, common mental disorders, post-traumatic stress disorders, depression and suicidality [2].

According to Manglio [3], the result of sexual abuse, particularly among girls is the risks associated with unprotected sex with multiple partners and sex trading. In addition, child sexual abuse is significantly related to depression, low self-esteem, psychological problems such as personality disorders, dissociative disorders, self-injurious behavioural problems in adolescence.

Traumatized family members require professional support, parenting skills and on-going therapy, while physical and financial strain can cause high levels of stress in families and children with disabilities. The caring process relies on the nurses' knowledge, understanding and insights but also on the ordinariness of being a human being [4]. On the other hand, in 1991, Wakley found that it was not uncommon for doctors when faced with a sexual abuse case to feel a sense of panic, or not being fully equipped to deal with the emotive problems which are evoked by hearing about abusive episodes [5].

A study done in the United Kingdom by Harrison and Zohhadi [6] revealed that the impact of failing to fully understand the role of mental health needs and the provision of emotional care was apparent, while in Australia, the mixed attitudes of nurses to caring for people with mental illness such as their lack of knowledge and fear of saying 
the wrong thing resulted in people receiving limited mental health care from nurses [7].

Increasingly nursing students come into contact with severely traumatized people and it is not always possible to effectively discuss the physical and emotional impact that these experiences have on them. A consequence of this is that student nurses could be left with unresolved issues and a sense of failure, while the conflicting attitudes towards people with disabilities often ranges from disregard to rejection but then also shift towards wanting to make a positive contribution or sympathy [1]. Reflecting on experiences is therefore an important aspect for nurses and could help to overcome this problem.

Reflective journal writing can be viewed through many different lenses: as a form of self-expression, a record of events or a form of therapy [8]. Although much can be learned from reflections, it is also a way to make sense of and exploring often messy and confused events while focusing on the thoughts and emotions that accompany them. A psychodynamic approach therefore includes all the theories in psychology that see human functioning based upon the interaction of drives and forces within the person particularly unconscious and between the different structures of a person [9]. Mentally revisiting and portraying the experience in writing can be an important first step in focusing on the feelings and emotions which accompanied those experiences and an opportunity to get rid of negative feelings while learning from the positive ones [10].

Mental illness is not only a major psychosocial problem in South African society but the consequences of child abuse affect children and adults in various ways. Nurses are not only responsible for recognizing and identifying, but are bound by law to report child abuse of any nature [11]. Psychosocial nursing forms an integral part of training at the University, towards a bachelor's degree and registration as a Professional Nurse. Students complete 4,000 clinical hours during four years of study in general hospitals, midwifery, community clinics and psychiatric units. Because of the sensitivity around children, only final year students are placed in a children's psychiatric ward of a psychiatric facility, an outpatient unit for emotionally, sexually and physically traumatized children as well as in a residential care facility for intellectually disabilities.

A problem was identified when, despite theoretical knowledge of diagnosis and predisposing factors regarding child abuse and practical experience in general, psychiatric, community nursing and midwifery, students expressed their fear, anxiety and reluctance to work in those institutions. The facilitator was challenged about the need to work there and what they could possibly learn from those people whom they cannot even imagine having a conversation with. The question then was whether student nurses were emotionally prepared for the reality of coming face to face with severe emotionally, intellectually or physically traumatized children in the community?

\section{Purpose and Objective of the Study}

The purpose of this study was to explore and describe final year psychosocial nursing students' reflections, feelings and experiences during clinical placement with intellectually, emotionally and physically traumatized children.

\section{Research Design and Method}

The purpose of the qualitative, descriptive study was to explore and describe final year psychosocial nursing students' reflections, personal feelings and experiences during clinical placement with children who are traumatized by accidental, environmental and non-accidental injury or abuse. A purposive sample comprised of written and marked narratives applicable to the experiences while in particular institutions and extracted from psychosocial reflective journals of final (4th) year students until saturation of information was reached. Qualitative methods focus on the qualitative aspects of meaning, experience and understanding, and they study human experience from the viewpoint of the research participants in the context in which the action takes place [12]. The researcher used bracketing by becoming the writer of the students' reflections and a psychodynamic approach to make sense of the interactions within and between people's unconscious structures [9].

\section{Data Collection}

Permission was granted and ethical clearance obtained from the Human Research Ethics Committee of the University (M150636). The ethical principle of non-maleficence [13] was applied to ensure that no harm occurred to the respondents during the research process. An information leaflet was handed to the students and informed consent was obtained from 16 students to use the narratives from their reflective journals. The data was collected from their reflective journals after the final marks were published; therefore their responses could not be detrimental to their progress. Because of the small number of students and only a few male students in the course, confidentiality and anonymity was ensured by not using names or student numbers. Biographical data which may identify students was therefore not collected.

\section{Rigor}

Only one group's experiences were explored, which limits the transferability of the findings, but students' reflections and feelings were truthfully represented [14].

Credibility refers to the confidence in the truth of the data and interpretations of them, but truth of the data in this study may be subjective due to emotional involvement of the students.

Confirmability is concerned with establishing that data represents information participants provided and findings reflect the participants' voice and not that of the inquirer/researcher. However when bracketing was used, the researcher's voice was identified in the narrative. Reflection on negative feelings and difficulties in practice confirmed the data collected and did not seem to influence how the students recorded such feelings.

\section{Analysis of Information}

Embedded in Reissman's [15] approaches to narrative analysis, is thematic analysis which relies on categorizing accounts or aspects of accounts that are being told. In this study, written narratives were explored; however there is a possibility that the product of the narrative analysis also becomes a narrative by the researcher [16]. Data collection and thematic analysis occurred concurrently as the journals were read and re-read to extract the following themes and sub-themes (Table 1) that stood out from the narratives: 
Citation: Van den Heever AE (2017) "The Thing with Non-Physical Fatigue is that you can't Get Rid of it with Rest": Psychosocial Nursing Students Reflect on Their Clinical Placement, South Africa. J Nurs Care 6: 381. doi:10.4172/2167-1168.1000381

Page 3 of 6

\begin{tabular}{|c|c|c|}
\hline Themes & Subthemes & Narratives \\
\hline The students were disillusioned & $\begin{array}{l}\text { Disillusions } \\
\text { Making sense of the world, of themselves, life and people; us and them? } \\
\text { Annoyed by their own inability to respond }\end{array}$ & "People just turn a blind Eye" \\
\hline An emotional rollercoaster ride & $\begin{array}{l}\text { Physically demanding; tired; emotionally exhausting; } \\
\text { Can't get rid of it with rest To feel or not to feel? } \\
\text { Mixed emotions and conflicting feelings pity, crying, angry, happy, smiling, "disgusting", } \\
\text { empathy, fear }\end{array}$ & $\begin{array}{l}\text { "Negative feelings weighed } \\
\text { me down" }\end{array}$ \\
\hline $\begin{array}{l}\text { They struggled with unresolved } \\
\text { ethical issues }\end{array}$ & $\begin{array}{l}\text { Ethical and moral dilemmas; Ashamed to be a nurse; Being a man } \\
\text { Unresolved feelings; Abused or Abuser? Regress to own childhood } \\
\text { Think about their own childhood }\end{array}$ & "Talk about it or not?" \\
\hline $\begin{array}{l}\text { Conflicting professional and moral } \\
\text { dilemmas }\end{array}$ & $\begin{array}{l}\text { On being a Carer: } \\
\text { Good enough nurse and midwife? } \\
\text { Bad mother or parent, abused or the abuser? Who is to blame? } \\
\text { Negligence? nurse, midwife, parents, carers, child, society or legal system }\end{array}$ & "I was angry at the mother" \\
\hline Moving from disgust to gratitude & $\begin{array}{l}\text { Eye opener, admiration for those who do good; they helped me; appreciation, understanding } \\
\text { of lessons learned; Some justice restored; Restored faith in humanity }\end{array}$ & $\begin{array}{l}\text { "I am grateful for the } \\
\text { experience" }\end{array}$ \\
\hline
\end{tabular}

Table 1: Themes and subthemes derived from the narritives of students' reflective journals.

\section{The students were disillusioned}

Most of the students were disillusioned because things were not as good as they believed it could be. They felt shocked and disappointed and they no longer believed in people while the world felt unreal to them:

\section{"It had never occurred to me that anybody can do that to another"}

"As sad and harsh as it might sound, not everyone is meant to be a parent"

"It is unfair to feel this way about all people. I felt as if I lost hope in humanity"

Some students lost faith in their own judgement and abilities, while most of the students identified with the patients' inabilities, disabilities or being "retarded". How could they help someone to pick up the pieces if they themselves are also falling apart?

"It was a shocking experience and made me ask questions about me as a man"

"Little did I know that I would not only be frustrated but I would also feel extremely incompetent?"

\section{An emotional rollercoaster ride}

The sudden and extreme changes in their emotions, angry and scared the one moment just to feel happy the next moment, were physically and emotionally exhausting.

"It was a scary, frustrating and sad place to be in the beginning."

"Through something as small and simple as remembering my name, he gave me so much"; "It made me happy to see her smile"

Emotional exhaustion is a chronic state of physical and emotional depletion which could result from excessive job and personal demands or continuous stress; a person may lose interest and motivation in what let them to become a nurse in the first place [17].

A number of students felt trapped and wanted to escape from intolerable feelings and a rollercoaster of emotions; others did not know how to feel or how not to feel at all. However, by suppressing those feelings, they dissociated into a state of not feeling and not knowing.

"I curled tighter into myself and blocked all my thoughts out. I refused to continue feeling and thinking, my emotions ceased to develop, they were retarded"

Some students seemed scared and in an attempt to tolerate their fear and bottled up aggression they seemed to project the rage into their colleagues.

\section{"I could have STRANGLED this doctor"}

In Freud's theory [18], the ego uses defense mechanisms to handle conflict between the id and the superego to reduce tension, for example being scared of a dog, is seen as anxiety of something in reality. But on the other hand an unconscious fear could be seen as students being unaware of the nature of the threat, and uncertainty whether a threat exists at all:

"I was worried that I would not cope emotionally"; "It raised terrifying feelings in me"

\section{They struggled with unresolved ethical issues}

One student wanted to get out of there. "Free me!"; "Let me out of here!"; "End a life or save a life?" Most of the students were worrying, questioning and thinking a lot but found it hard to make sense of the patients and themselves. They felt responsible for what happened to the patients, while others felt guilty to feel those feelings.

"......and we continue to infringe on these children's rights" 
Citation: Van den Heever AE (2017) "The Thing with Non-Physical Fatigue is that you can't Get Rid of it with Rest": Psychosocial Nursing Students Reflect on Their Clinical Placement, South Africa. J Nurs Care 6: 381. doi:10.4172/2167-1168.1000381

Page 4 of 6

"Sterilisation: do good no harm - I am still uneasy about this law"

"I remember thinking to myself that if I gave birth to such a child, I would end its life"

"These children are a full-time job, they require chronic therapy and they stress finances"

"I ask myself questions but could not get the answers"

"It can be questioned if it is ethically correct to resuscitate a child who might end up with some sort of disability?"

Some students felt disgusted by the damaged bodies and minds in some of the patients and seemed to be ashamed about their reaction or guilty about questioning whether someone with a severe disability should be resuscitated. This is confirmed by the shame and toxic shame that patients can identify with about their own deformed bodies and that they can feel as a result of physical and sexual abuse [19]. A similar process of projective identification described by Klein [20] could also get into the nursing students and therefore genuine awareness of the way we feel about a situation can help us to understand ourselves and the patients in that moment [21].

\section{Conflicting professional and moral dilemmas}

"Who am I? The abused or the abuser?"

Being in their fourth year, the general expectation was that students had been exposed to most illnesses and conditions. Some of them were mothers themselves, and delivered at least 15 babies at that point of their training. Above all, they wondered whether they are being abused by the system or are they seen as the abusers.

The students wanted to blame someone, but who was to blame? They projected their own feelings of incompetence and disabilities into the system, but they themselves were part of the health system. Most students or doctors further denied the existence of those feelings by not saying anything or avoid talking about it.

\section{"The child wants to speak, but her jaw is tight"}

"The doctor ignored her"

"Not only one of us asked how the mother was feeling"

"The mother knew about the abuse and wouldn't do anything"

With the unconscious use of projection, the students could defend against their own anxiety and unpleasant feelings by attributing the badness into the abused, but also identified with the abusive and neglectful feelings that were projected onto them by the patients. Defense mechanisms can falsify reality [20], therefore in their minds; the students became the neglectful abuser, bad mother or midwife.

"My anger was directed towards midwives" "I felt pushing the blame onto the midwife"

"She was in labour for $24 \mathrm{~h}$, then forceps - he is now profoundly mentally handicapped"

"You need to ensure as a midwife to give proper care - because most of them are due to some negligence during pregnancy or birth"

"It was stark reality and this was close to home - I was generally disappointed at the care during antenatal visits"

\section{From disgust to gratitude}

Their eyes opened slowly and most of the students expressed surprise at how these unfortunate people and their circumstances could teach them facts about life that they were unaware of. The sense of denigration that they felt in the beginning, changed to admiration of the carers and those parents who were committed to care for their unfortunate children. Eventually their own roles were idealised by wanting to be good mothers, and good nurses.

"An eye opener as I journeyed in the shoes of the innocent"

"This inspired me - I too want to be so caring"

"You walk out of here every day with great appreciation for life"

"It restored some of my faith in humanity"

"I gave her a doll and she stopped crying; it was quite a nice feeling"

Some students thought about their own childhood and regressed to a helpless state of infancy by feeling insignificant or unskilled and incompetent but had renewed appreciation for their own parents and a happy childhood [10].

\section{"I am grateful for my parents and the way I was raised"}

"It once again made me reflect on my childhood and to see the emotions I experienced when I was young"

Others somatised their emotions by feeling physically paralyzed, disabled or retarded on the one hand and realizing that they are human after all on the other hand realised that this was a journey of discomfort, exhaustion, growth and revelation and what became clear, is that they learned a lot about themselves and remembered the reasons for choosing to be a nurse.

"I learned a lot about psychiatry and myself"; "I will be a better midwife because of psychiatry"; "I need to be more aware of myself and my personality"

"I am too hard on myself"; "I realised that I am a sensitive being"

\section{Results and Discussion}

The researcher became the reflective writer of the students' story while having to question her own role in the transference. The apparent psychodynamic pattern of defense mechanisms [1] used by the students and my own anxiety may have influenced the ability to think or to answer the many questions. Have I also become part of the abusive system in the students' minds?, therefore also angry with me? Or, like society in general, also became desensitized? What were the students' expectations of psychosocial nursing? I wondered whether the students felt that their voices were not heard? Did we even listen to each other?

"I think the mother felt like she had not been 'heard'..."

"I silently shed a tear" "The child wants to speak, but her jaw is tight - how much dignity and grace does she have!"

Have they also been failed or were their own rights and need for care disrespected in any way?

"We deny many kids their right and freedom to be loved and cared for"

"I was almost in tears because all along I thought he was unable to speak or comprehend what was happening around him" 
The challenge to become a reflective practitioner was not without its hurdles. It was no longer possible for the nurses to accept everything at face value, and the effort required to do this should not be underestimated. At times there seemed not much of a difference between the students and the patients with hidden bits of themselves showing from time to time. A build-up of emotions made them feel physically and emotionally sick and incapable of helping one another. Although younger, inexperienced nurses are less genuine with patients or themselves [21], by reflecting on their experiences, the students in this study had an opportunity to express their feelings in an honest attempt to make sense of their experiences.

It is not uncommon for an abused person to feel helpless, fearful and insignificant [19] . Emotional abuse, deliberate humiliation, the instillation of fear and shame similar to what students in this study experienced, can damage emotional health [19]. Commonly survivors of trauma and sexual abuse blame themselves very harshly and feel responsible for what happened to them. Further suggestions are that compassion fatigue could be due to psychological and physiological responses when working with and caring for traumatized people and can lead to secondary trauma, or vicarious traumatization and burnout [17]. The only way the students seemed to protect them against the unbearable anxiety, and to cope with feelings of guilt, shame and anger, was to unconsciously made use of defense mechanisms [1].

However, as one student said: "You can defend against it but you can't get rid of it with rest".

The students' use of defense mechanisms were as a result of what they have experienced in their environment, which did not leave them feeling good; [1] instead they were left with a vague, low-level anxiety which was difficult to explain, but never the less seemed to be associated with feelings of confusion and helplessness. This might have had an effect on the way they viewed themselves and the world as well as on their belief systems and emotional well-being [17].

Having to endure and experience the effects of trauma could have resulted in symptoms of vicarious traumatization which are parallel to the post-traumatic stress suffered by survivors: [17]. However, a person's reaction when exposed to an emotionally loaded event could be amplified, which is grounded in a traumatic past or present experience [17] and can drain emotional energy.

It was hard for the researcher to make sense of the blur between what was the patients' or the students' words, and how that tied in with their experiences. She was left wondering how student nurses could be emotionally empathetic and mindful, while they themselves felt like falling apart? But on the other hand, how could their confusion and frustration be known, unless they had a space to talk?

\section{Limitation}

The reflections of only one group of students were explored.

\section{Recommendations}

The use of reflective journal writing should be encouraged during clinical placement. Langley and Brown [22] write that the practice of reflective journaling contributes to important learning outcomes for online graduate nursing students. They identify four learning outcomes that are evident in nursing and education literature; professional development, personal growth, empowerment, and facilitation of the learning process. Reflective journaling strengthened their self- confidence, thereby helping the students become change agents in their work environments [22].

By analysing the narratives of these journals, the importance of supervision, self-reflection and support became clear:

"What I liked was how all our allocations ended with a de-briefing session from the sister in charge - that helped with reflection and clarification" and that is why "I need to have someone I can talk to and confide in when I feel overwhelmed by work"

- Support in the form of group discussions before placement as well as empathetic listening and understanding while in placement to process their fears is recommended

- The staff of the clinical facilities should be supported to create an understanding of the students' emotions and vulnerabilities while in practice

- A follow up study should explore the effects on students' views after supportive measures were implemented

\section{Conclusion}

Although for some students, "Writing this journal was more enriching than just telling a story", others expressed emotional fatigue and internal conflict between life and just being alive. The students struggled with the role they might play as a midwife in the lives of babies that they deliver, and being a good-enough mothers to protect their own children from abuse. But they had renewed admiration for carers, parents and institutions that become their homes. Their relief was recognised when they eventually understood the reasons for placement and when the factors influencing these events became clearer.

"The exciting part for me was to be able to make the connection between theory and practice and the ability to reflect on it in a meaningful way"

Although the placement was not what the students have anticipated it to be, they seemed free from mistaken beliefs or foolish hopes about people and life as a whole, in other words, free from illusion towards the end of their clinical placement.

\section{References}

1. Uys LR, Middleton L (2014) Mental health nursing: A South African perspective 6thedition, Cape Town, Juta, 226-228.

2. Stein DJ, Seedat S, Herman A (2008) Lifetime prevalence of psychiatric disorders in South Africa. Br J Psych 192: 112-117.

3. Manglio R (2009) The impact of child sexual abuse on health: A systematic review of reviews. Clin Psychol Rev 29: 647-657.

4. Berg A, Hallberg IR, Norberg A (1998) Nurses' reflections about dementia care, the patients, the care and themselves in their daily caregiving. Int J Nurs Stud 35: 271-282.

5. Wackely G (1991) Sexual abuse and the primary care doctor; the problem in primary health care: Springer Science and Business media, Psychosexual Medicine Series, pp: 1-10.

6. Harrison A, Zohhadi S (2005) Professional influences on the provision of mental health care for older people within a general hospital ward. J Psychiatr Ment Health Nurs 12: 472-480.

7. Reed F, Fitzgerald L (2005) The mixed attitudes of nurses to caring for people with mental illness in a rural general hospital. Int J Ment Health Nurs 2005: 249-257.

8. Chase S (2005) Narrative inquiry: Multiple lenses, approaches, voices. In: Denzin, NK, LincolnYS (eds.) The SAGE handbook of qualitative 
Citation: Van den Heever AE (2017) "The Thing with Non-Physical Fatigue is that you can't Get Rid of it with Rest": Psychosocial Nursing Students Reflect on Their Clinical Placement, South Africa. J Nurs Care 6: 381. doi:10.4172/2167-1168.1000381

Page 6 of 6

research. 3rdedition. Thousand Oaks, London, Sage Publications, New Delhi, pp: 651-679.

9. McLeod SA (2007) Psychodynamic approach.

10. Boud D (2001) Using journal writing to enhance reflective practice: New directions for adult and continuing education, Summer 2001, John Wiley and Sons, Inc.

11. South Africa Government Gazette (2007) Children's Act No. 38 of 2005, Juta Ltd.

12. Polit DF, Beck CT (2012) Nursing research generating and assessing evidence for nursing practice. Lippincott Williams and Williams, USA

13. Dhai A, McQuoid-Mason D (2011) Bioethics, human rights and health law: Principles and practice, Juta, Cape Town, pp: 14-15

14. Begley AM (2008) Truth-telling, honesty and compassion: A virtue-based exploration of a dilemma in practice. Int J Nurs Pract 14: 336-341.

15. Reissman CK (2008) Narrative methods for the human sciences Thousand Oaks, Sage Publications, London.
16. Clandinin DJ, Connelly FM (2000) Narrative enquiry: Experience and story in qualitative research, Jossey-Bass publishers, San Francisco.

17. Phillips SB (2004) Group interventions for treatment of psychological trauma. Module 7: Countertransference, Effects on the group therapist working with trauma, New York, pp: 196-222

18. Freud S (1856-1939) Psychodynamic perspective.

19. Mollon P (2002) Shame and Jealousy: The Hidden Turmoils, Karnac Books (Ltd.), USA

20. Klein M (1946) 'Notes on some schizoid mechanisms.' In: The Writings of Melanie Klein, Volume III, Hogarth, 1-24.

21. Van den Heever AE, Poggenpoel M, Myburgh CPH (2015) Nurses perceptions of facilitating genuineness in a nurse-patient relationship. Health SA Gesondheid 20: 109-117.

22. Langley ME, Brown ST (2010) Perceptions of the use of reflective journals in online graduate nursing education. Nurs Educ Perspect 3 1: 12. 